\title{
TIME SERIES MODELLING OF PAN EVAPORATION: A CASE STUDY IN THE NORTHEAST INDIA
}

\author{
DABRAL P.P. \\ JHAJHARIA D.* \\ MISHRA P. \\ HANGSHING L. \\ DOLEY B.J.
}

\author{
Department of Agricultural Engineering \\ North Eastern Regional Institute of Science and Technology \\ (Deemed University) \\ Nirjuli, Itanagar-791109 \\ Arunachal Pradesh, India
}

Received: 03/01/14

Accepted: 27/01/14

Available online: 04/02/2014

*to whom all correspondence should be addressed: e-mail: jhajharia75@rediffmail.com

\section{ABSTRACT}

In the present study, a monthly time series model was developed for pan evaporation $\left(E_{\text {pan }}\right)$ in Jorhat (Assam), northeast India. We assume that the $E_{\text {pan }}$ series can be decomposed into deterministic and stochastic components, and a turning point test was used to identify the presence of a trend component in the series. A trend-free $E_{p a n}$ time series was further obtained by eliminating the trend component from the original $E_{\text {pan }}$ time series, and later used in identifying the periodic component using Fourier series analysis. Results show that the first three harmonics explained the total variance by $88.2 \%$. Before modelling the stochastic dependent component, the periodic component was removed from the time series. In the stochastic dependent component modelling, the moving average (MA) model of order 2 was found suitable on the basis of minimum value of the Bayesian information criterion (BIC). The independent stochastic component was modelled using the normal distribution function. Overall, a very good agreement is observed between generated and historical records, with the Nash-Sutcliffe coefficient being equal to 0.98 .

Keywords: Pan Evaporation; Stochastic modelling; Moving average model; Jorhat; India.

\section{Introduction}

A data sequence ordered in time is called a time series. A time series model can be divided into two components- deterministic and stochastic. The deterministic component is used for prediction of the time and chance independent future events, while the stochastic component is used for determination of the chance and chance dependent effects. Deterministic components are either periodic or nonperiodic in nature. The non-periodic component is characterized by its trend and jump characteristics. Trends characteristics could be either of an increasing type or of a decreasing type. The period of nature of a deterministic component is characterized by its cyclic pattern, which exhibits an oscillatory movement and it is repeated over a fix interval of time. A stochastic component consists of irregular oscillation and random effects, which are not accountable physically, and is described by probabilistic concept. To enable analysis, a time series must exhibits smooth behavior, otherwise the result may be erratic. The importance of time series analysis has become a major tool in engineering hydrology. It is being used either for building mathematical model to generate synthetic hydrologic records or to forecast the occurrence of hydrologic events. Other uses of time series analysis include detection and modelling of trend and shifts that maybe apparent in hydrologic records, the filling of missing data, and 
extension of hydrologic records. A time series represent a set of observations, which measure the variation in time of some dimension of a phenomenon, such as precipitation, evaporation, wind speed, river flow etc. Among others, Toth et al., (2000); Jha et al., (2003); Raja Kumar and Kumar, (2007); Dabral et al., (2008); Sherring et al., (2009) and Kumar and Kumar, (2010) used time series for modelling various hydrological parameters in recent past. Mishra and Desai (2005) used ARIMA and multiplicative Seasonal Autoregressive Integrated Moving Average (SARIMA) models to forecast droughts based on the procedure of model development.

Evaporation is one of the most important components of the hydrologic cycle and its accurate estimation is essential in various water resources projects. Kumar et al. (2012), in their review work, highlighted the importance of evapotranspiration in the precise determination of water requirements of various crops and their irrigation scheduling. However at the same time, it is very difficult to obtain reliable estimates of the evaporation. The rate of evaporation can be measured in several ways out of which evaporation pan or evaporimeter is the most widely used instrument for its measurement. The United States Weather Bureau (USWB) Class ' $A$ ' pan is the most widely used pan throughout the world (Allen et al., 1998). Indian Meteorological Department (IMD) has also adopted USWB Class ' $A$ ' evaporimeter for the measurement of pan evaporation. Pan evaporation series is periodic - stochastic in nature. Therefore, modelling of the pan evaporation series by decomposing into periodic and stochastic component provides an improved methodology for short and intermediate forecasting. Gupta and Kumar (1994) collected the weekly evaporation data (1974-1992) of Palampur and conducted stochastic analysis of weekly evaporation data. They showed that evaporation is periodic-stochastic in nature. The time series of evaporation had combination of a harmonic deterministic part and second order AR model. They generated evaporation values for 988 weeks from the developed model and the values of mean and standard deviation of generated series fell in 95\% confidence limits. Gupta and Singh (2004) conducted the study on stochastic modelling of evaporation in arid region of India. In their study, monthly stochastic models were developed using data obtained from Bikaner and Bellary station, located in arid region of India. The autoregressive model developed for each station was then validated for two years in advance, and predicted values were then compared with the observed evaporation data. The correlation coefficient between predicted and observed evaporation series was found to be 0.99 for the stations, which showed the perfectly modelled structure for the evaporation time series.

Northeast India has great economic dependence on crops like paddy, tea and forest products, and any major changes in the water budget may have major consequences on hydrologic processes. The studies relating to the evaporation over northeast India are very important for irrigation planning. Jhajharia et al., (2006) performed the correlation analysis between the pan evaporation and the various other meteorological parameters, i.e., temperature, relative humidity, wind speed, etc., under the humid environments of Jorhat (Assam). Since no study was available on time series analysis of pan evaporation for Jorhat site located in the northeastern state of Assam, (India), the present study was undertaken with the following specific objectives:

i. To develop time series model of pan evaporation.

ii. To validate the developed model.

\section{Methods and Material}

\subsection{Study Area and Collection of Data}

Monthly pan evaporation data of Jorhat (Tocklai) were collected from Tea Research Association, Jorhat, Assam (Longitude $94^{\circ} 12^{\prime} \mathrm{E}$, Latitude $26^{\circ} 47^{\prime} \mathrm{N}$ and elevation $96.50 \mathrm{~m}$ above mean sea level) from the year 1965 to 2005. The study area is located in the humid region of north-east India, one of the highest rainfall-receiving regions on the Earth, and which has some of the sub-continent's last remaining rain forests. The location map of the Jorhat site is shown in Fig. 1. The monsoon rainfall increases from south to north and also from west to east over subtropical Assam (Jhajharia et al., 2012). The monthly pan 
evaporation data from the year 1965 to 2000 were selected for time series analysis and the monthly data for five years (2001-2005) were used in the model validation in the present study.

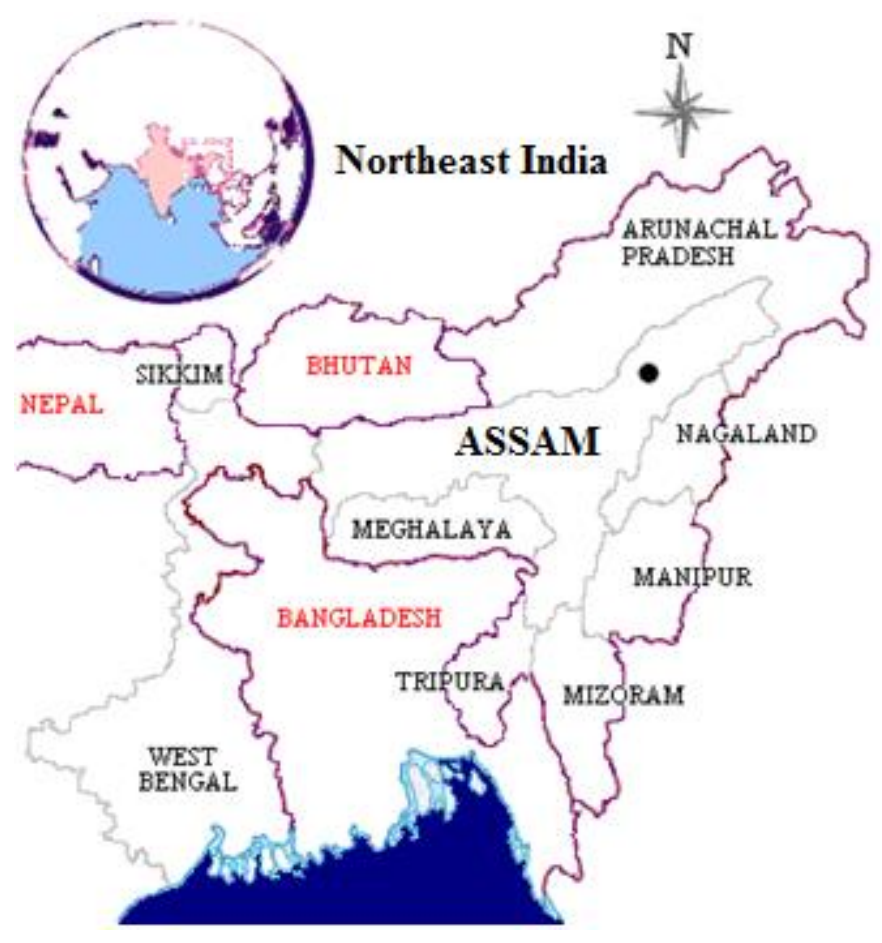

Figure 1. Location of Jorhat (Tocklai) site in Assam, northeast India

\subsection{Time Series Models}

Mathematically, a discrete time series is denoted by $X_{t}$, where $t=1,2,3 \ldots$ etc., and $X_{t}$ are at equidistant time interval and decomposed by additive type. The additive form provides a reasonable model in most cases and is expressed as:

$\mathrm{X}_{\mathrm{t}}=\mathrm{T}_{\mathrm{t}}+\mathrm{P}_{\mathrm{t}}+\mathrm{S}_{\mathrm{t}}+\mathrm{a}_{\mathrm{t}}$

Where, $T_{t}=$ deterministic trend component, $P_{t}=$ deterministic periodic component, $S_{t}=$ stationary stochastic dependent component, $a_{t}=$ Stationary stochastic independent component, $t=1,2,3 \ldots . . . N$, $\mathrm{N}=$ total number of values and $\mathrm{X}_{\mathrm{t}}=$ Monthly pan evaporation data.

Since the model is applied to stochastic component, which is treated as random variable, the trend and periodic components were first removed from the time series. To obtain representative stochastic model of the time series, identification and detection of each component is necessary. Each of the model components have been analyzed and determined by following step wise procedure.

\subsection{Trend Component $\left(T_{t}\right)$}

Steady and regular movement in a time series through which the values are, on an average, either increasing or decreasing, is term as trend. Thus, the purpose of identifying a trend is to determine if the values of a random variable generally increase (or decrease) over some period in statistical terms (Onoz and Bayazit, 2003; Wu et al., 2007). Trends can be identified through the parametric and nonparametric tests, and both the tests are widely used in the fields of hydro-meteorology and climatology. First, we performed the turning point test for detecting the trend in pan evaporation time series in the present study. But, the parametric tests need the data to be independent and normally distributed. Therefore the Mann-Kendall (MK) test, a rank-based nonparametric test for assessing the significance of a trend, has been also used in this study. The nonparametric tests are better than parametric tests as reported by various researchers (Vousoughi et al., 2013; Dinpashoh et al., 2013). The MK test provides a 
robust test for trend, free from assumptions about mathematical form of the trend or the probability distribution of errors (Hasanean, 2001; Chattopadhyay et al., 2011).

\subsubsection{Turning point test}

Kottegoda (1980) presented the turning point test for testing the trend. A null hypothesis of no trend in the series was adapted. The test is applied to derive the number of turning points in a data. A turning point exists when $x_{i}$ is either greater than preceding and succeeding values or less than both. Thus, any of the condition for a variate $x_{i-1}<x_{i}>x_{i+1}$ or $x_{i-1}>x_{i}<x_{i+1}$ gives a turning point. The procedure of the test is outlined as follows.

i. Data were arranged in order of their occurrence.

ii. Either of the condition $x_{i-1}<x_{i}>x_{i+1}$ or $x_{i-1}>x_{i}<x_{i+1}$ was applied to ascertain how many turning points were there in the series.

iii. Let the total number of turning points be $p$, where $p=$ peaks + troughs.

iv. Expected number of turning points in the series is

$$
E(p)=\frac{2}{3} \times(N-2)
$$

where $\mathrm{N}$ is the total no of data.

$v$. Variance of $p$ is

$$
\operatorname{Var}(p)=\frac{(16 \times N-29)}{90}
$$

vi. P can be expressed as a standard normal form

$$
\mathrm{Z}=\frac{(\mathrm{P}-\mathrm{E}(\mathrm{p}))}{\sqrt{\operatorname{Var}(\mathrm{p})}}
$$

vii. If calculated value of $Z$ is within the critical range of \pm 196 for $5 \%$ level of significance, the hypothesis of no trend was accepted.

If trend is present, then $T_{t}$ was removed by regression or any other method. After removing the trend, a trend free series was obtained as:

$Y_{t}=X_{t}-T_{t}=P_{t}+S_{t}+a_{t}$

\subsubsection{Non-parametric Mann-Kendall test}

The non-parametric MK method (Mann, 1945; Kendall, 1975) is used for identifying the trends in pan evaporation and is based on the test statistic, $\mathrm{S}$, defined as follows:

$S=\sum_{k=1}^{n-1} \sum_{j=k+1}^{n} \operatorname{sgn}\left(x_{j}-x_{k}\right)$

where $n$ is the number of observations and $x_{j}$ is the $j^{\text {th }}$ observation and $\operatorname{sgn}(\cdot)$ is the sign function which can

$$
\operatorname{sgn}(\theta)=\left\{\begin{array}{ccc}
1 & \text { if } & \theta>0 \\
0 & \text { if } & \theta=0 \\
-1 & \text { if } & \theta<0
\end{array}\right.
$$

The mean and variance of the $\mathrm{S}$ statistic, under the assumption that the data are independent and identically distributed, are given by the following expressions:

$E(S)=0$ 
$V(S)=\frac{n(n-1)(2 n+5)-\sum_{i=1}^{m} t_{i}\left(t_{i}-1\right)\left(2 t_{i}+5\right)}{18}$

where $m$ is the number of groups of tied ranks, each with $t_{i}$ tied observations. The MK statistic, designated by $Z$, can be computed as

$Z=\left\{\begin{array}{cc}\frac{S-1}{\sqrt{\operatorname{Var}(S)}} & S>0 \\ 0 & S=0 \\ \frac{S+1}{\sqrt{\operatorname{Var}(S)}} & S<0\end{array}\right.$

If the value of $M K$ test statistic lies within the limits \pm 1.96 , i.e., $-Z_{1-\alpha / 2} \leq Z \leq Z_{1-\alpha / 2}$, then the null hypothesis of no trend can be accepted at the $5 \%$ level of significance using a two-tailed test. Otherwise, the null hypothesis can be rejected and the alternative hypothesis can be accepted at the $5 \%$ level of significance (Jhajharia et al., 2013).

\subsection{Periodic Component}

The periodic component in a time series is deterministic in nature having the property to repeat itself at regular intervals. The periodic component in the series $Y_{t}$ was determined by harmonic analysis. Base period and number of significant harmonics are to compute periodic component by harmonic analysis. Base period in the series was identified through autocorrelogram which has the graphical relationship of autocorrelation function $r_{k}$ against lag $k$. The periodic component of mean monthly value in series $Y_{t}$ was estimated by following equation:

$\mu_{\tau}=m_{x}+\sum_{j=1}^{m} A_{j} \cos \frac{2 \pi j \tau}{w}+B_{j} \sin \frac{2 \pi j \tau}{w}$

Where, $\mu_{\tau}=$ periodic component in mean monthly value, $m_{x}=$ mean of series $Y_{t}=1,2,3 \ldots, N$ with $N$ as the total number of discrete values of pan evaporation, $A_{j}$ and $B_{j}=$ Fourier coefficients of mean series, $\tau=1,2,3 \ldots \mathrm{w}$ with $\mathrm{w}$ as basic period of the series $=1,2,3 \ldots \mathrm{m}$ with $\mathrm{m}$ as member of significant harmonics, and $w=12$ for monthly pan evaporation.

The parameters $A_{j}$ and $B_{j}$ were estimated by the following equations:

$$
\begin{aligned}
A_{j} & =\frac{2}{W} \sum_{\tau=1}^{W} m_{\tau} \cos \frac{2 \pi j \tau}{w} \\
B_{j} & =\frac{2}{W} \sum_{\tau=1}^{W} m_{\tau} \sin \frac{2 \pi j \tau}{w}
\end{aligned}
$$

Where, $m_{\tau}=$ individual monthly mean values,

$$
m_{\tau}=1 / n \sum_{\tau=1}^{n} x_{p}, \tau
$$

$y_{p, \tau}=$ values of monthly pan evaporation in the year $p$ and at the position $\tau$ in the year with $p=1,2,3 \ldots n$ and $\tau=1,2 \ldots w$ and $n=$ number of years pan evaporation.

The periodic component in the standard deviation was estimated by using the similar relationship (Eq. 8 and 9) as discussed above and Fourier coefficients were also determined. Fourier coefficients for mean and standard deviation were determined up to six harmonics as suggested by Mutreja (1986). The actual 
numbers of significant harmonics to be fitted in the series $X_{t}$ were determined through an analysis of variance. Variance $h_{t}$ explained by each harmonic is given in the form of written equation below:

$h_{j}=\left(A_{j}^{2}+B_{j}^{2}\right) / 2$

$\Delta p_{\mathrm{j}}=\left(\right.$ variance of $\left.\mathrm{h}_{\mathrm{j}}\right) / \mathrm{s}^{2}$

It represents part of the variation of periodic component explained by $\mathrm{j}^{\text {th }}$ harmonic, where, $\mathrm{s}=$ variance of the standard deviation of the monthly data. Having decided the number of harmonics to be fitted to the 12 estimated values of periodic mean and periodic standard deviation, the periodicity of the series $Y_{t}$ was removed using the following equation:

$Y_{p t}^{\prime}=\frac{y_{p t}-\mu_{\tau}}{\sigma_{\tau}}$

Since, Eq.11 is an approximately a standard variable, its mean $\mathrm{Y}_{\mathrm{av}}$ and standard deviation $\mathrm{S}_{\mathrm{y}}$ were found and the standardized stochastic component was obtained from the following equation:

$\epsilon_{p t}=\frac{Y_{p t}^{\prime}-Y_{a v}}{s_{y}}$

\subsection{Stochastic Component}

The stochastic component is constituted by various random effects, which cannot be estimated exactly. In the present study model parameters of autoregressive model $(A R(p))$ moving average $(M A(q))$, autoregressive and moving average model $(\operatorname{ARMA}(p, q))$ and autoregressive integrated moving average model (ARIMA $(p, d, q))$ were determined using SPSS-16 software. The best fit model was identified on the basis of the minimum value of Bayesian information criterion (BIC).

Independent stochastic component series $\left(a_{t}\right)$ was obtained by subtracting model value of stochastic component from actual value of the stochastic component.

To check the independence of $a_{t}$, the Portmanteau test formulation by Ljung and Box (1978) was carried out. For modelling the independent stochastic component $\left(a_{t}\right)$, normal probability distribution function was fitted to $a_{t}$ series as suggested by Chow et al. (1988). The transformed $a_{t}$ series, in terms of $R_{t}$ series, can be represented as:

$\mathrm{R}_{\mathrm{t}}=\mu_{\mathrm{t}}+\sigma_{\mathrm{t}} \times \mathrm{z}_{\mathrm{t}}$

Where, $R_{t}=$ transformed $a_{t}$ series, $\mu_{t}=$ mean of the $R_{t}$ series, $\sigma_{t}=$ standard deviation of the $R_{t}$ series and $\mathrm{z}_{\mathrm{t}}=\mathrm{a}$ random component with zero mean and unit variance (available from standard table).

\subsection{Evaluation of Time series model}

Using the developed model data were generated for the period 1965 to 2000 for model testing purpose and from the year 2001 to 2005 for model validation. Generated data were evaluated quantitatively using statistical measures, such as, absolute error, relative error, and Nash-Sutcliffe coefficient ( $\left.E_{N S}\right)$, which are described below.

Absolute error=|Generated value-Historical value|

Relative error $=\frac{\text { Absolute error }}{\text { Historical value }} \times 100$

$E_{N S}=1-\left(\frac{\sum_{t=1}^{n}\left[X_{o b s}(t)-X_{c a l}(t)\right]^{2}}{\sum_{t=1}^{n}\left[X_{o b s}(t)-X_{a v g}(t)\right]^{2}}\right)$ 


\section{Results and Discussion}

\subsection{Deterministic Modelling}

For identification of trend component in the monthly evaporation series, first turning point test was carried out. The hypothesis of no trend in the series was formulated and checked using the test statistics. The results of the turning point test are discussed as follows. For 420 nos. of values of pan evaporation at Jorhat; the values of the $p$, the $E(p)$ and the $\operatorname{Var}(p)$, as described in section 2.3.1, obtained through the turning point test are found to be $165,278.67$ and 74.34 , respectively. Results indicate the presence of trend component in the monthly pan evaporation series of Jorhat because the calculated value of $Z$ obtained through the turning point test is found to be -13.18 , which lies outside the critical range of \pm 1.96 at $5 \%$ level of significance. Thus the hypothesis of no trend was rejected, and there is decreasing trend in the pan evaporation time series under the humid environments of Jorhat. Further, we used the non-parametric MK test to identify the trend in the pan evaporation series. The value of the test statistics obtained through the MK test is found to be -2.91 , which confirms the result of decreasing trend in the pan evaporation time series over Jorhat.

Using regression analysis, equation of trend component $\left(T_{t}\right)$ was determined which is as follows:

$\mathrm{T}_{\mathrm{t}}=71.5-0.015 \times \mathrm{t}$

Where, $\mathrm{t}$ value $=-209$ (January, 1965) to +209 (December, 2000).

After removing the trend, a trend free series was obtained as Eq.2.

Autocorrelogram of the series $Y_{t}$ (trend free) was developed for identification of base period for the development of autocorrelogram, the auto correlation function $\left(r_{k}\right)$ of the series $Y_{t}$ for lag 1 to 50 was calculated and is shown in Fig. 2. The autocorrelogram of series $Y_{t}$ show that autocorrelation function are significantly different from zero, which indicates that all the monthly values are mutually dependent. The peak and trough of the autocorrelogram show that the series $Y_{t}$ has a periodic component with a base period of 12 months.

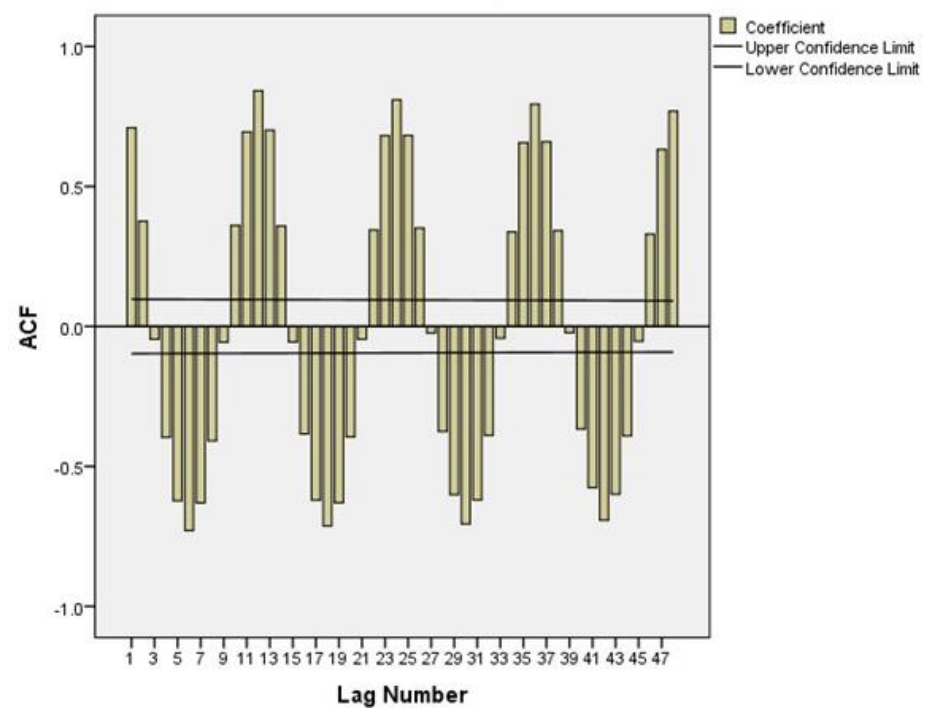

Figure 2. Auto correlogram of series $Y_{t}$

Fourier decomposition of periodic component and cumulative periodogram of monthly evaporation at Jorhat are shown in Table 1 and Fig. 3, respectively. Results show that the first three harmonics explain a total variance of $88.2 \%$ for the Jorhat station. Therefore, the other harmonics were ignored. Periodic means and periodic standard deviations were computed. The periodicity of the series $Y_{t}$ was removed. The remaining $S_{t}$ series were tested for stationary behavior and model identification. 
Table 1. Fourier decomposition of periodic component of monthly pan evaporation at Jorhat

\begin{tabular}{ccccc}
\hline Order & $\mathrm{Aj}$ & $\mathrm{Bj}$ & Explained variance (\%) & Cumulative explained variance (\%) \\
\hline 1 & -30.3526 & 3.28433 & 83.4 & 83.4 \\
\hline 2 & -6.91667 & -3.48 & 4.3 & 87.7 \\
\hline 3 & 2.433333 & -2.28333 & 0.5 & 88.2 \\
\hline 4 & 0.516667 & 0.115467 & 0.0 & 88.2 \\
\hline 5 & 0.419267 & 2.835467 & 0.0 & 88.2 \\
\hline 6 & -0.81667 & 0 & 0.1 & 88.3 \\
\hline
\end{tabular}

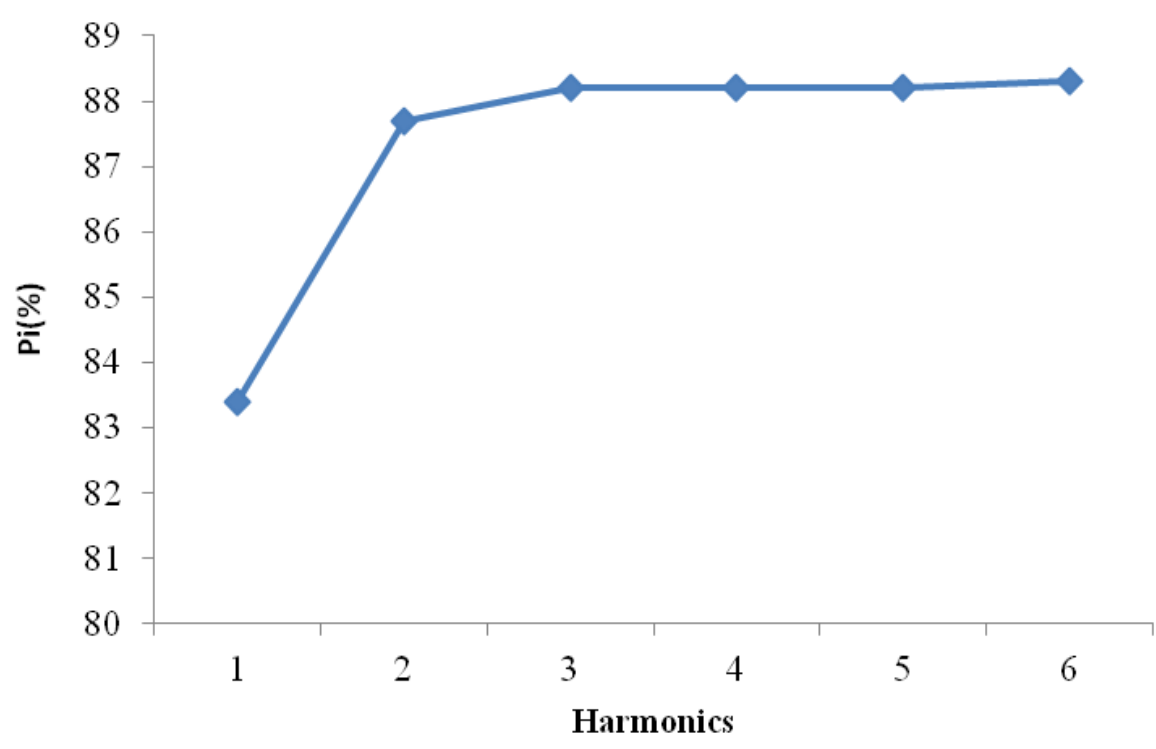

Figure 3. Cumulative periodogram of monthly pan evaporation at Jorhat

\subsection{Stochastic Modelling}

It is observed that the first autocorrelation and partial auto correlation function at lag 1 to 5 cross the 95\% confidence limit (Fig. 4 and Fig. 5). Anderson (1976) observed that with the help of autocorrelogram and partial autocorrelogram, the true identification of the actual process might not be possibly obtained. He therefore, suggested that other models should be tried for the selection. Therefore AR, MA, ARMA and ARIMA models were also tried in this study. The value of BIC statistics was found to be minimum $(-0.044)$ in case of MA (2) model. Therefore, the $2^{\text {nd }}$ order moving average model was considered as suitable.

Portmanteau test formulated by Lijung and Box (1978) and turning test indicated that $a_{t}$ series consist of independent and identically distributed variables. For modelling the independent stochastic component, normal probably distribution function was fitted to $a_{t}$ series. The calculated chi square value was found to be 10.416 , which is less than that of the tabulated value 10.60 at $0.5 \%$ level of significance. This indicates that $a_{t}$ series is fitted to normal probability distribution function. 


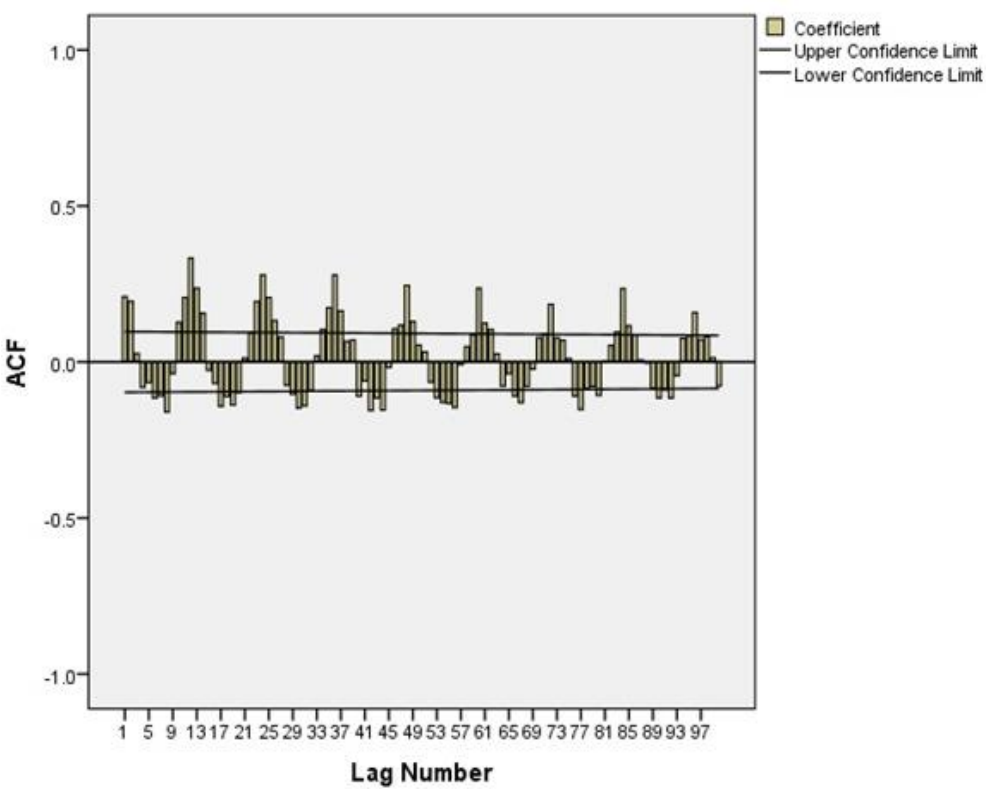

Figure 4. Auto correlogram of series St with twice S. E. limit

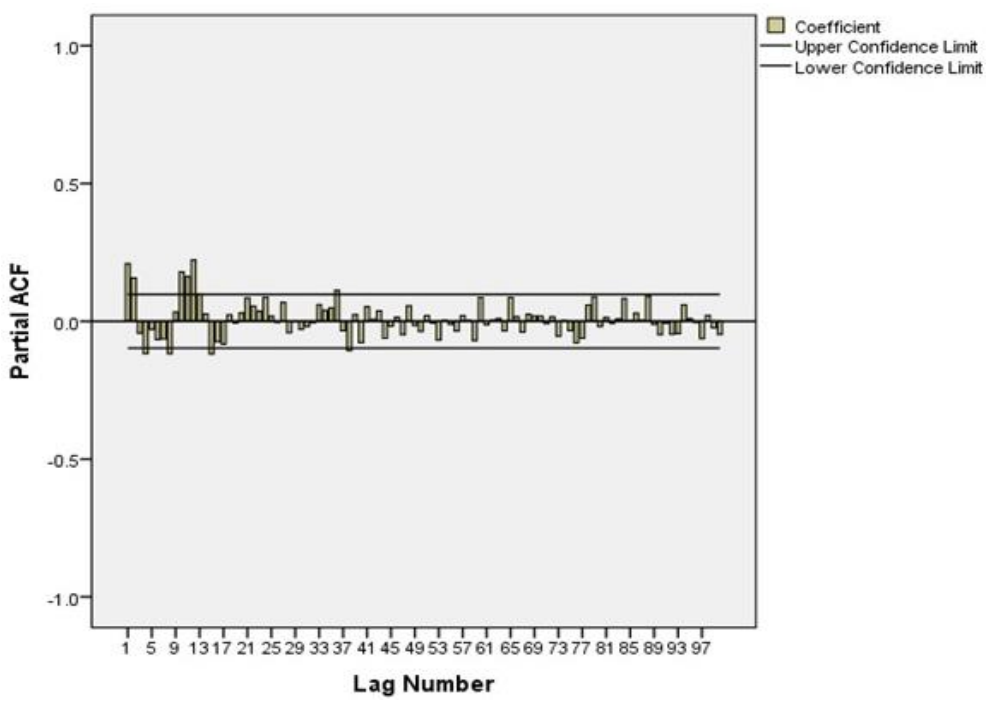

Figure 5. Partial auto correlogram of series St with twice S. E. limit

The transform $a_{t}$ series, in terms of $R_{t}$ series is represented as:

$\mathrm{R}_{\mathrm{t}}=\mathrm{z}_{\mathrm{t}}$

Time series was developed by substitution of the values of deterministic and stochastic components in Eq. 1. The decomposition model of the time series $X_{t}$ is then express as:

$X_{t}=(71.35-0.015 t)+\left\{0.01+(-30.3526) \cos \left(\frac{2 \pi}{12}\right) \tau+(3.2843) \sin \left(\frac{2 \pi}{12}\right) \tau+(-6.91667) \cos \left(\frac{4 \pi}{12}\right) \tau+(-3.48) \sin \left(\frac{4 \pi}{12}\right) \tau+2.433 \cos \left(\frac{6 \pi}{12}\right) \tau+(-2.2833) \sin \left(\frac{6 \pi}{12}\right) \tau\right\}+\left(0.164 R_{t-1}+0.217 R_{t-2}\right)+2 t$

The qualitative assessment was made by the comparison of autocorrelation function of the historical and regenerated series. The autocorrelogram up to 192 lags of historical and generated time series is presented in Fig. 6 and 7, respectively. It is seen from the figures that the properties propagated in the generated series are similar to the historical series. 


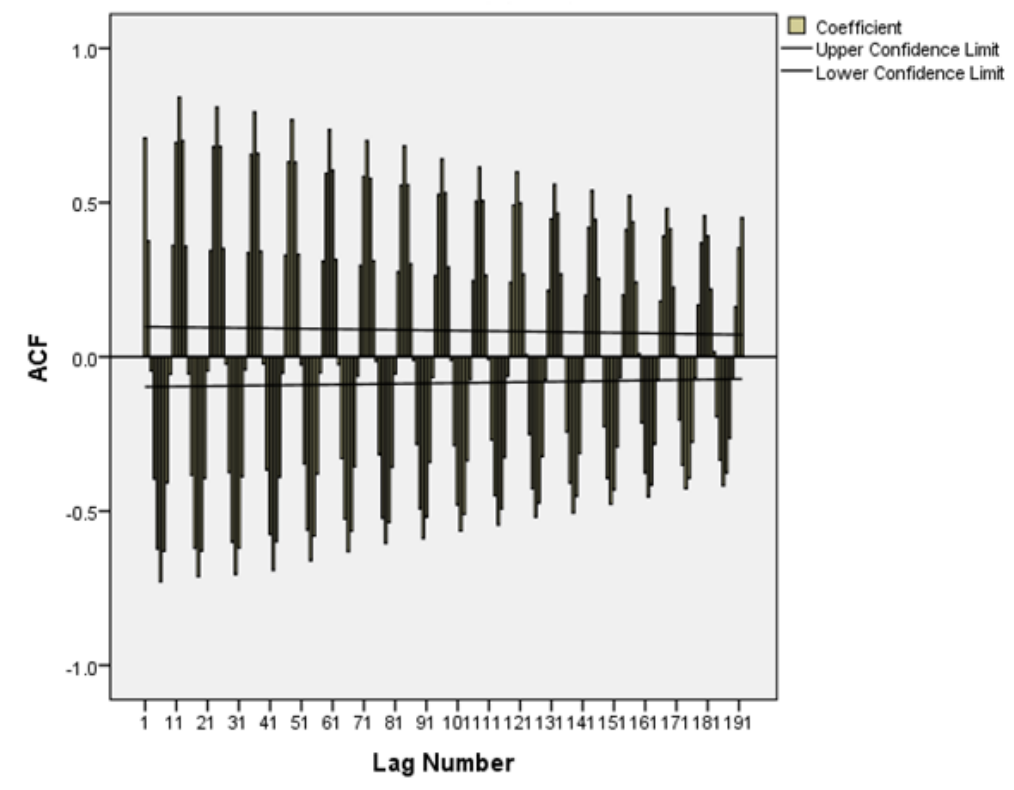

Figure 6. Auto Correlogram of series $\mathrm{X}_{\mathrm{t}}$

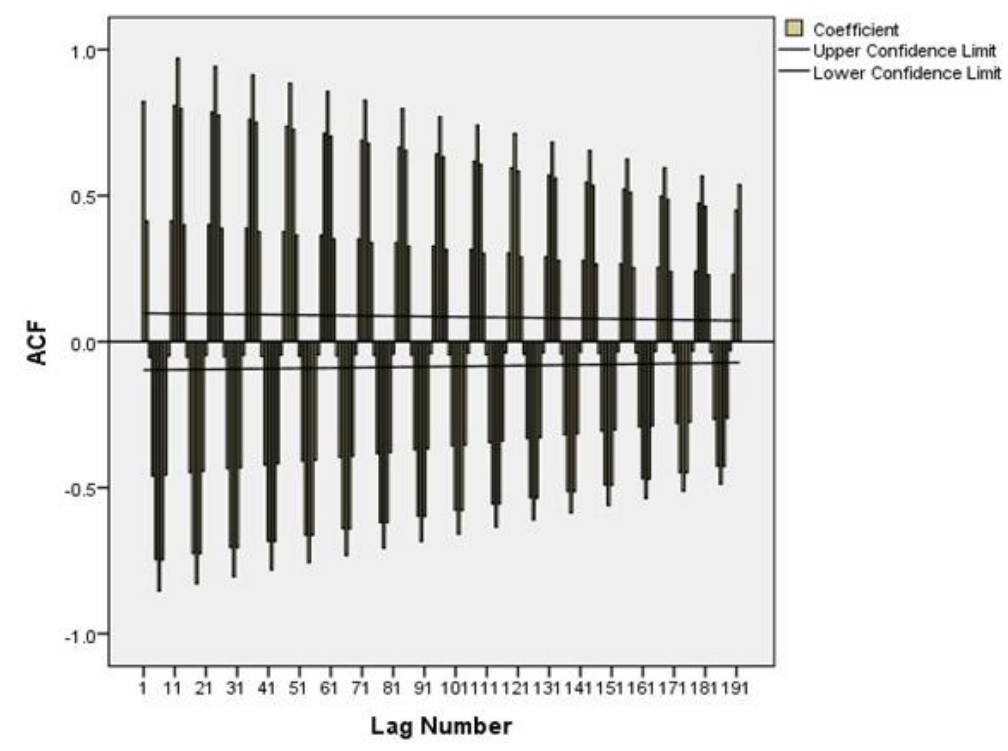

Figure 7. Auto correlogram of generated series

\subsection{Model Assessment}

Results of the time series model were evaluated quantitatively to assess the regeneration performance. The model was evaluated with regards to several statistical measures such as absolute error, relative error and Nash-Sutcliffe coefficient (Table 2). The mean and standard deviation of the generated series (1965 to 2000) are found to be $72.35 \mathrm{~mm}$ and $22.8 \mathrm{~mm}$, respectively, which are close to the mean $(71.35 \mathrm{~mm})$ and standard deviation $(24.56 \mathrm{~mm})$ of the historical series of the pan evaporation. The Nash-Sutcliffe coefficient was found equal to 0.98 , which indicates a high degree of model fitness.

The mean monthly values of pan evaporation from (1965-2000) of historical data and generated sequence were used for comparison. The respective relative and absolute errors of all the calendar 
months were calculated for comparison, and are given in Table 2. The absolute errors are in the range of 0.2 to $9.6 \mathrm{~mm}$. Relative errors are found to be comparatively higher for the months January, February, April and October.

Table 2. Mean monthly pan evaporation of historical and generated data series (1965-2000) along with errors

\begin{tabular}{|c|c|c|c|c|c|}
\hline \multirow[t]{2}{*}{ Month } & \multirow{2}{*}{$\begin{array}{c}\text { Mean of } \\
\text { historical data } \\
(\mathrm{mm})\end{array}$} & \multirow{2}{*}{$\begin{array}{c}\text { Mean of } \\
\text { generated data } \\
(\mathrm{mm})\end{array}$} & \multicolumn{2}{|c|}{ Errors } & \multirow{2}{*}{$\begin{array}{c}\text { Nash Sutcliff } \\
\text { coefficient }\end{array}$} \\
\hline & & & Absolute $(\mathrm{mm})$ & Relative (\%) & \\
\hline January & 36.2 & 38.5 & 2.3 & 6.4 & 0.98 \\
\hline February & 48.6 & 57.6 & 9.0 & 18.4 & \\
\hline March & 80.9 & 84.2 & 3.3 & 4.1 & \\
\hline April & 89.1 & 98.6 & 9.6 & 10.7 & \\
\hline May & 95.0 & 97.0 & 2.0 & 2.1 & \\
\hline June & 91.5 & 92.8 & 1.3 & 1.4 & \\
\hline July & 94.3 & 92.3 & 2.0 & 2.1 & \\
\hline August & 93.1 & 92.8 & 0.3 & 0.3 & \\
\hline September & 77.1 & 73.3 & 3.7 & 4.8 & \\
\hline October & 64.9 & 57.8 & 7.1 & 10.9 & \\
\hline November & 46.6 & 45.9 & 0.6 & 1.4 & \\
\hline December & 37.0 & 37.2 & 0.2 & 0.4 & \\
\hline
\end{tabular}

Time series model was used for prediction of five years values of pan evaporation, i.e., for the years from 2001 to 2005 . The predicted values of monthly pan evaporation along with the historical values for five years from the year 2001 to 2005 are shown in Fig. 8.

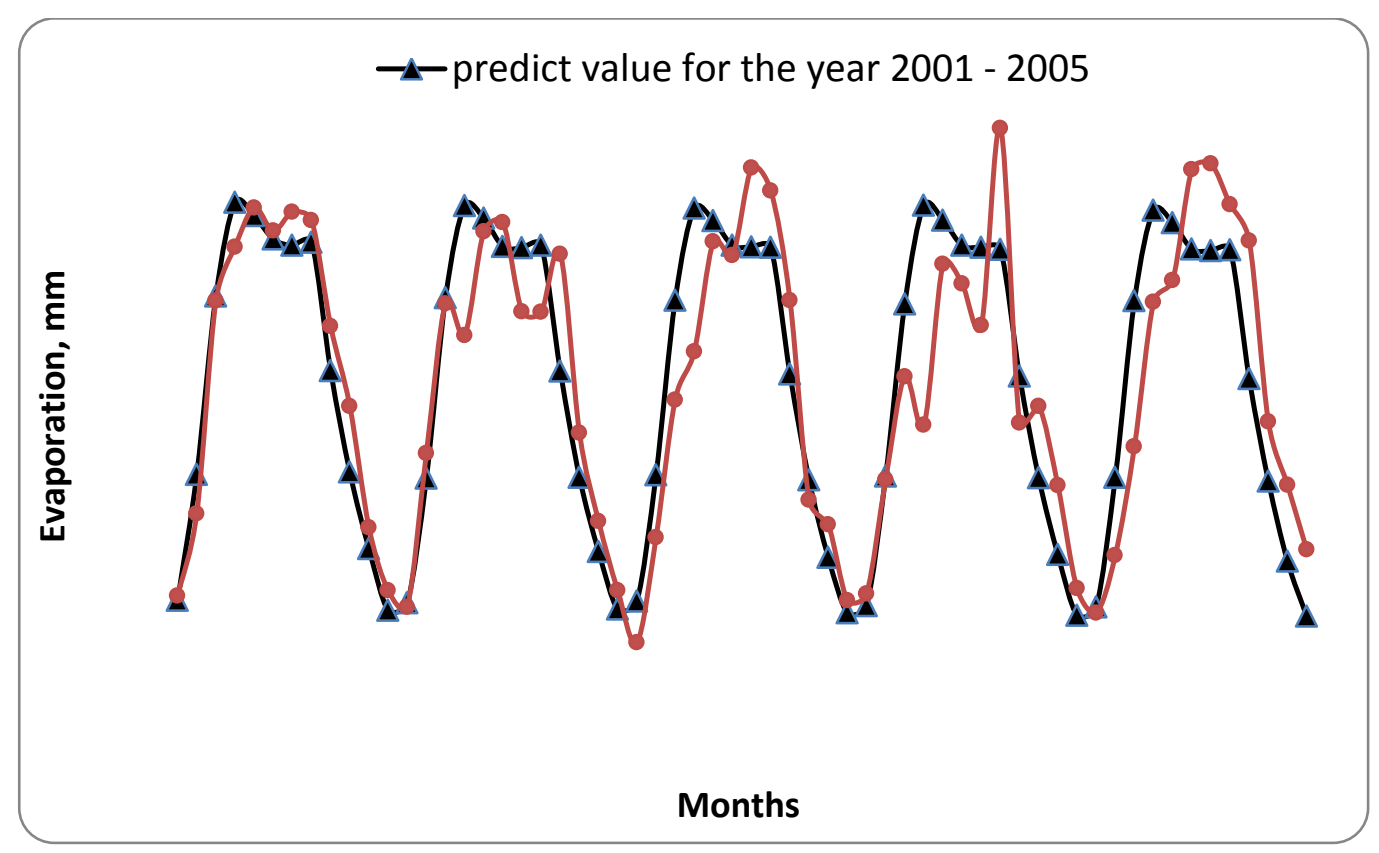

Figure 8. Observed and predicted value of pan evaporation for the years 2001-2005

The annual mean of the predicted monthly pan evaporation is $68.84 \mathrm{~mm}$, which is close to the mean value of $68.71 \mathrm{~mm}$ of the historical value. The absolute errors are in the range of 0.5 to $8.4 \mathrm{~mm}$. Relative errors are found to be comparatively higher for the months of March and April. The Nash-Sutcliffe 
coefficient is observed to be 0.98 indicating a high degree of model fitness to the observed data (Table 3).

Table 3. Mean monthly pan evaporation of historical and generated data (2001-2005) series along with errors

\begin{tabular}{|c|c|c|c|c|c|}
\hline \multirow[t]{2}{*}{ Month } & \multirow{2}{*}{$\begin{array}{c}\text { Mean of } \\
\text { historical data, } \\
\mathrm{mm}\end{array}$} & \multirow{2}{*}{$\begin{array}{c}\text { Mean of } \\
\text { generated data, } \\
\mathrm{mm}\end{array}$} & \multicolumn{2}{|c|}{ Errors } & \multirow{2}{*}{$\begin{array}{c}\text { Nash Sutcliffe } \\
\text { coefficient }\end{array}$} \\
\hline & & & Absolute $(\mathrm{mm})$ & Relative (\%) & \\
\hline January & 36.2 & 35.6 & 0.5 & 1.4 & 0.98 \\
\hline February & 49.5 & 51.7 & 2.2 & 4.4 & \\
\hline March & 71.1 & 75.6 & 4.5 & 6.4 & \\
\hline April & 76.2 & 84.8 & 8.7 & 11.4 & \\
\hline May & 89.4 & 91.1 & 1.8 & 2.0 & \\
\hline June & 91.3 & 90.4 & 0.9 & 1.0 & \\
\hline July & 90.7 & 89.9 & 0.8 & 0.9 & \\
\hline August & 94.5 & 92.0 & 2.5 & 2.6 & \\
\hline September & 79.7 & 75.2 & 4.5 & 5.7 & \\
\hline October & 60.8 & 57.8 & 3.0 & 5.0 & \\
\hline November & 49.4 & 46.2 & 3.2 & 6.4 & \\
\hline December & 38.0 & 36.0 & 2.0 & 5.3 & \\
\hline
\end{tabular}

\section{Conclusions}

Evaporation is one of the most important components of the hydrologic cycle and its forecasting is crucial in any water resource development project. In this study, the monthly pan evaporation series over Jorhat (Assam) is found to be trend-periodic-stochastic in nature. The mean and the standard deviation of the generated series were found close to the mean and standard deviation of the historical series of the pan evaporation. The Nash-Sutcliffe coefficient (0.98) also indicated high degree of model fitness. The developed model was validated by predicting pan evaporation for next five years, and the result indicated a high degree of model fitness to the observed data as well. Jhajharia et al., (2007) have reported that climatic information through any kind of time series modelling may help the farmers and policy-makers in short-term and long-term agricultural planning. Thus, the results obtained of time series modelling of evaporation under the humid environments would enable us to adapt to the climate change in the bio-diversity rich region of northeast India.

\section{Acknowledgements}

The authors thank the Tocklai Tea Research Association (Jorhat) for providing the meteorological data for this study. We are also grateful to the anonymous reviewers, Dr R. Kumar and Dr. I. Pechlivanidis for their useful comments that improved the quality of the paper.

\section{References}

Allen R.G., Pereira L.S., Raes D and Smith M. (1998). Crop evapotranspiration, Guidelines for computing crop water requirements. FAO Irrigation and Drainage Paper, FAO Rome, Italy.

Anderson O.D. (1976). Time series analysis and forecasting, the Box-Jenkins approach, Butterwarth and co. London.

Chattopadhyay S., Jhajharia D. and Chattopadhyay G. (2011), Trend estimation and univariate forecast of the sunspot numbers: Development and Comparison of ARMA, ARIMA and Autoregressive Neural Network models, Comptes Rendus Geoscience, 343, 433-442. 
Chow V.T., Maidment D.R. and Mays L.W. (1988). Applied Hydrology. McGraw-Hill, New York.

Dabral P.P., Pandey A., Baithuri N. and Mal B.C. (2008), Developed stochastic modelling of rainfall in Humid Region of North East India, Water Resource Management, 22, 1395-1407.

Dinpashoh Y., Mirabbasi R., Jhajharia D., Abianeh H.Z. and Mostafaeipour A. (2013), Effect of Short Term and Longterm Persistence on Identification of Temporal Trends, Journal of Hydrologic Engineering, On line available on 18 March 2013. doi:10.1061/(ASCE)HE.1943-5584.0000819.

Gupta M. and Singh R.V. (2004), Stochastic modelling of evaporation in arid region of India, Hydrology Journal (IAH), 27(3-4), 1-13.

Gupta R.K. and Kumar R. (1994), Stochastic analysis of weekly evaporation values, Indian Journal of Agricultural Engineering, 4(3-4), 140-42.

Hasanean H.M. (2001), Fluctuations of surface air temperature in the eastern Mediterranean, Theor. Appl. Climatol., 68, 75-87.

Jha V. Singh R.V. and Bhakar S.R. (2003), Stochastic modelling of soil moisture, Journal of Agricultural Engineering, 40(4), 51-56.

Jhajharia D., Chattopadhyay S., Choudhary R.R., Dev V., Singh V.P. and Lal S. (2013), Influence of climate on incidences of malaria in the Thar Desert, north-west India, International Journal of Climatology, 33, 312-325.

Jhajharia D., Fancon A.K. and Kithan S.B. (2006), Correlation between pan evaporation and meteorological parameters under the climatic conditions of Jorhat (Assam), Journal of Indian Water Resources Society, 26(1\&2), 39-42.

Jhajharia D., Roy S. and Ete G. (2007), Climate and its variation: A case study of Agartala, Journal Soil Water Conservation, 6(1), 29-37.

Jhajharia D., Yadav B.K., Maske S., Chattopadhyay S. and Kar A.K. (2012), Identification of trends in rainfall, rainy days and $24 \mathrm{~h}$ maximum rainfall over subtropical Assam in northeast India, Comptes Rendus Geoscience, 344, 1-13

Kendall M.G. (1975). Rank Correlation Methods. (4th edn) Charles Griffin: London.

Kottegoda N.T. (1980). Stochastic Water Resources Technology. The Macmillan Press LTD., London.

Kumar M. and Kumar D. (2010), Developed multiplicative ARIMA modelling of monthly stream flow of Betwa river, Indian Journal of Soil conservation, 38(2), 62-68.

Kumar R., Jat M.K. and Shankar V. (2012), Methods to estimate reference crop evapotranspiration - A review, Water Science Technology, 66(3), 525-535.

Ljung M.G. and Box G.E.P. (1978), On a measure of lack of fit in time series models, Biometrika, 65(2), $297-303$.

Mann H.B. (1945), Non-parametric tests against trend, Econometrica, 33, 245-259.

Mishra A.K. and Desai V.R. (2005), Drought forecasting using stochastic models. Stochastic Environmental Research and Risk Assessment (Springer), 19, 326-339.

Mutreja K.N. (1986). Applied hydrology, New Delhi, Tata Mcgraw Hill Publishing Company Limited, 959 P.

Onoz B. and Bayazit M. (2003), The power of statistical tests for trend detection, Turk. J. Eng. Environ. Sci., 27, 247-251.

Raja Kumar K.M. and Kumar D. (2007), Developed a time series modelling of daily rainfall during north-east monsoon season of Baptala, Andra Pradesh, Indian Journal of Soil Conservation, 35(1), 21-25.

Sherring A., Hafiz Ishtiyaq Amin A.K. Mishra and Mohd A. Alam (2009), Developed a stochastic time series modelling for prediction of rainfall and runoff in Lidder catchment of South Kashmir, Journal of Soil and Water Conservation, 8(4), 11-15.

Toth E., Brath A. and Montanari A. (2000), Comparison of short term rainfall prediction models for real time flood forecasting, Journal of Hydrology, 239, 132-147.

Vousoughi F.D., Dinpashoh Y., Aalami M.T. and Jhajharia D. (2013), Trend analysis of groundwater using nonparametric methods (case study: Ardabil plain), Stochastic Environmental Research and Risk Assessment (SERRA), 27, 547-559.

Wu Z., Huang N., Long S.R. and Peng C.K. (2007), On the trend, detrending, and variability of nonlinear and nonstationary time series, Proceedings of the National Academy of Sciences, 104, 14889-14894. 